$16^{\text {th }}$ International Conference on

AEROSPACE SCIENCES \& AVIATION TECHNOLOGY,

ASAT - 16 - May 26 - 28, 2015, E-Mail: asat@ mtc.edu.eg Military Technical College, Kobry Elkobbah, Cairo, Egypt

Tel : +(202) 24025292 - 24036138, Fax: +(202) 22621908

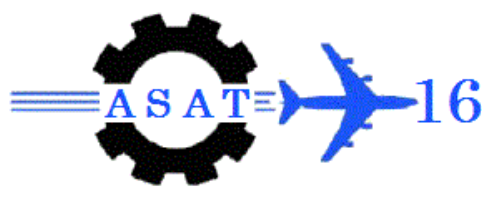

\title{
Investigation of Dual-Thrust Rocket Motor with Sonic Flow through an Intermediate Nozzle
}

\author{
Amr M. El-Nady ${ }^{1} \quad$ Ahmed M. Sarhan ${ }^{2} \quad$ Mohamed A. Al-Sanabawy ${ }^{3}$ \\ and \\ Mahmoud Y. Mohamed ${ }^{3}$
}

\begin{abstract}
:
The Dual-Thrust Rocket Motors (DTRMs) are the most widely used solid propulsion system for anti-tank guided missiles. DTRM with intermediate nozzle is a special type of this system. Depending on the internal conditions, the flow through the intermediate nozzle can be sonic, subsonic or reversed.

The objective of this paper is to understand the internal ballistics (IB) and phenomena of DTRM with sonic intermediate nozzle. In this study, a mathematical model describing the performance of this DTRM is derived from the main governing equations of internal ballistics. Also, a set of experiments is conducted using a developed test motor to inspect the physics of DTRM with sonic intermediate nozzle and assess the mathematical model validity.

Results of the mathematical model have shown a good agreement compared with those from the experimental studies.
\end{abstract}

Keywords: Internal Ballistics, Solid Propulsion, Dual Thrust Rocket Motor, Test Rocket Motor.

\section{Introduction:}

Compared with other rocket propulsion systems, solid propellant rocket motors (SPRM) are easier to manufacture, handle and store, and lighter in weight. In addition, SPRMs do not require maintenance for their entire shelf life and they contain less components so their reliability is higher. All these advantages make them superior to all other propulsion systems for various military applications.

Traditional designs of SPRM yield a monotonic thrust-time profile namely, either progressive, regressive, or neutral [1]. However, if the motor design, propellant characteristics, and grain geometry are properly selected, SPRM can provide a wide variety of thrust-time profiles. Dual (high-low or boost-sustain) thrust profiles have been developed to meet the demands for anti-tank guided missiles. DTRMs can have various designs; each of which has a range of operation depending on the resulting thrust ratio (boost-to-sustain thrust ratio) [2].

DTRM with an intermediate nozzle is a special design that is argued to yield a high thrust ratio with a stable operation. As shown in Fig. 1, DTRM consists of two chambers containing solid propellant grains separated by an intermediate nozzle and final main external nozzle.

$1 \quad$ Egyptian Armed Forces, a5_elnady@ hotmail.com

2 Modern Academy at Maadi, Cairo, Egypt.

$3 \quad$ Egyptian Armed Forces. 


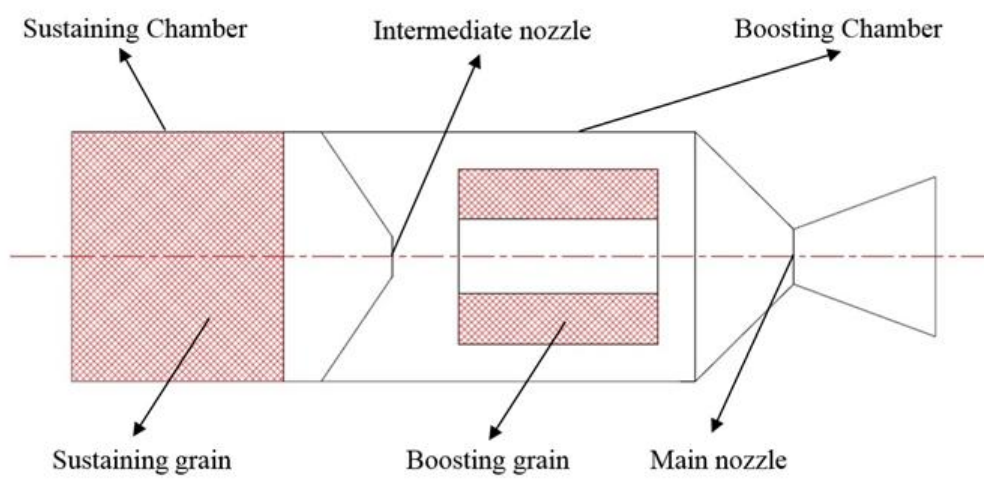

Figure 1 DTRM with an intermediate nozzle.

Both of the grains are ignited simultaneously starting the boost phase. The sustain phase follows as the booster charge burns out. During the boost (common function) phase, the combustion gas products flow through the intermediate nozzle and eventually through the main nozzle producing thrust. Depending on the internal flow conditions, the flow through the intermediate nozzle can be sonic, subsonic or reversed.

To the authors' best knowledge of the open literature, there has been no comprehensive study that investigated the phenomena in the DTRM with an intermediate nozzle. McFillin et al. [3] and Carrier et al. [4] focused on the internal ballistics of DTRM in the sustaining phase only. Only Manda [5] discussed the common operation of DTRM with an intermediate nozzle. However, the study was too concise to explain the rich details of this type of motors. This clear shortage of knowledge was the motivation behind the present study.

The objective of this paper is to understand the internal ballistics and phenomena of DTRM with sonic flow through the intermediate nozzle. In this study, a mathematical model describing the performance of DTRM in concern is derived from the main governing equations of internal ballistics (IB). In addition, a set of experiments is conducted so as to depict the details of the physics of this type of DTRM in both phases and assess the mathematical model validity.

\section{Theoretical Investigation:}

The developed mathematical model is based on satisfying the main governing principles of the gas thermo-fluid dynamics under the following assumptions [6]:

1. Combustion gases obey the perfect gas law.

2. Combustion gases are homogenous.

3. Steady state conditions.

4. Combustion gases flow is one dimensional, and isentropic.

5. Erosive burning and nozzle erosion are ignored.

6. Boosting and sustaining grains are made of the same propellant.

During the common function (boost phase), the flow in the intermediate nozzle becomes sonic if the pressure in the sustaining chamber $\left(P_{s, b}\right)$ is sufficiently higher than that in the boosting chamber $\left(P_{b, b}\right)$. More precisely, pressure difference between both chambers is attained such that the pressure ratio obeys the following inequality:

$$
\left(\frac{P_{s, b}}{P_{b, b}}>\left(\frac{k+1}{2}\right)^{\frac{k}{k-1}}\right)
$$

where $k$ is the specific heat ratio of the gas products. 
In this case the sustaining pressure $\left(P_{s, b}\right)$ value is independent of the boosting pressure $\left(P_{b, b}\right)$ value due to the occurrence of flow choking in the intermediate nozzle. The former can be calculated directly from the following equation:

$$
P_{s, b}=\left(K_{I_{S}} \cdot \rho_{s p} \cdot C^{*} \cdot r_{\circ}\right)^{\frac{1}{1-n}}=\left(\frac{S_{s}}{A_{\text {int }}} \cdot \rho_{s p} \cdot C^{*} \cdot r_{\circ}\right)^{\frac{1}{1-n}}
$$

where $K_{I_{S}}\left(=\frac{S_{S}}{A_{\text {int }}}\right)$ is the blocking factor of the sustaining chamber. $A_{\text {int }}$ is the throat area of the intermediate nozzle and $S_{s}$ is the burning surface area of the sustaining grain. $\rho_{s p}$ and $C^{*}$, are the propellant density and characteristic velocity, respectively. $r_{\circ}$ and $n$ are the burning rate constant and pressure exponent, respectively.

The boosting pressure in the boosting chamber $\left(P_{b, b}\right)$ can be calculated from the continuity equation i.e.

$$
\dot{m}_{D_{M}}=\dot{m}_{g_{b}}+\dot{m}_{D_{\text {int }}}
$$

where $\dot{m}_{D_{M}}$ is the discharge flow rate through the main nozzle. $\dot{m}_{g_{b}}$ is the generated flow rate in the boosting chamber. $\dot{m}_{D_{\text {int }}}$ is the discharge flow rate through the intermediate nozzle. By applying the IB principles, $P_{b, b}$ can be eventually obtained:

$$
\frac{P_{b, b} \cdot A_{M}}{C^{*}}=S_{b} \cdot \rho_{s p} \cdot r_{\circ} \cdot\left(P_{b, b}\right)^{n}+\frac{P_{s, b} \cdot A_{\text {int }}}{C^{*}}
$$

where $A_{M}$ is the throat area of the main nozzle and $S_{b}$ is the burning surface area of the boosting grain.

On the other hand, during the sustaining phase, the pressures in both boosting and sustaining chambers; $P_{b, s}$ and $P_{s, s}$, respectively, can be simply calculated using the following relations:

$$
\begin{gathered}
P_{s, s}=\left(K_{I_{s}} \cdot \rho_{s p} \cdot C^{*} \cdot r_{\circ}\right)^{\frac{1}{1-n}} \\
P_{b, s}=\frac{P_{s, s} \cdot A_{i n t}}{A_{M}}
\end{gathered}
$$

Equations (2), (4), (5) and (6) are used to estimate the combustion gas pressures in both boosting and sustaining chambers during both boost and sustain phases.

Finally, the thrust $(F)$ in both phases can be determined utilizing the following relation:

$$
F=P_{t} \cdot A_{M} \cdot \Gamma \cdot \sqrt{\frac{2 k}{k-1} \cdot\left(1-\left(\frac{P_{e}}{P_{t}}\right)^{\frac{k-1}{k}}\right)}+A_{e}\left(P_{e}-P_{a}\right)
$$

where $\Gamma$ is function of specific heat ratio $k, A_{e}$ is the main nozzle exit area, $P_{t}$ and $P_{e}$ are the total and exit pressures of the combustion gases, respectively, and $P_{a}$ is the atmospheric pressure. 


\section{Experimental Investigation:}

The objective of this experimental investigation is twofold. On the one hand, to comprehend the physics of internal ballistics taking place in a real DTRM. On the other hand, results of experiments are implemented to assess the validity of the developed mathematical model. For the latter objective, more than three experimental tests have been conducted for the operation of DTRM with sonic intermediate nozzle. The burning law for the selected propellant has been predicted based on experimental measurements and thermochemical calculations.

\subsection{Burning law of the used propellant:}

A Double-Base (DB) solid propellant was utilized in the experiments. The burning law of the used propellant was determined experimentally using a standard static firing test motor. Fifteen distinct tests were conducted at three different initial propellant temperatures ($20^{\circ}, 20^{\circ}$ and $\left.50^{\circ}\right)$ and five nozzle throat diameters $(7,8,9,10$ and $11 \mathrm{~mm})$. A thermo-chemical calculation package [7] was used to estimate the theoretical thermodynamic and chemical properties of the propellant combustion products. These properties include, among others, the specific heat ratio $(\mathrm{k})$, the gas constant $(\mathrm{R})$, the combustion temperature $\left(T_{c}\right)$, the characteristic velocity $\left(C^{*}\right)$, and the specific impulse $\left(I_{s p}\right)$. The results of the static firing tests were used to determine the burning law of the used propellant and was eventually found to have the form:

$$
r=0.0005113 . e^{0.00345\left(T_{s p}-20\right)} \cdot P_{c}^{0.183}
$$

where $T_{s p}\left[{ }^{\circ} \mathrm{C}\right]$ is the propellant temperature, $P_{c}[\mathrm{~Pa}]$ is the pressure of the combustion gases, and $r[\mathrm{~m} / \mathrm{s}]$ is the burning rate.

\subsection{The proposed test rocket motor:}

In the literature and in practice, there exist well-defined standard test motors for conventional, single thrust solid propulsion applications. However, as far as dual-thrust applications are concerned, there exist no specific definitions for a standard test motor in the open literature. This motivated the authors to develop a proposed test rocket motor TRM for applications involving DTRM with intermediate nozzle.

The preliminary design for this proposed TRM should include 4 main blocks which are the sustaining chamber, the intermediate nozzle, the boosting chamber, and the main nozzle.

To reach the final detailed design of the TRM, in addition to technical and practical considerations, a number of constraints has been specified:

1. Utilizing available on-shelf raw materials,

2. Satisfying maximum and minimum operating pressures,

3. Satisfying the sonic flow through the intermediate nozzle.

4. Providing neutral thrust in both boost and sustain phases.

The detailed design of the TRM is obtained as shown in Fig. 2. The boosting charge is made as tubular grain inhibited from the ends whereas the sustaining charge is a cigarette burning grain. Motor ignition is undertaken using one igniter placed in the sustaining chamber (upstream of the intermediate nozzle). A secondary igniter charge is placed downstream of the intermediate nozzle to insure ignition of the boosting grain. 


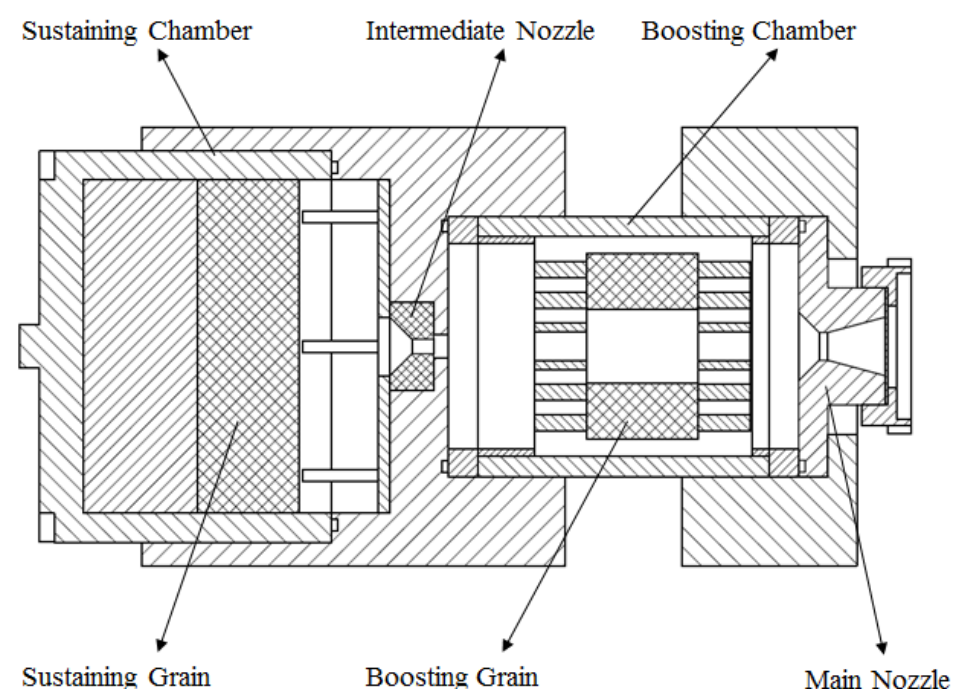

Figure 2 Design drawing of TRM

\subsection{Design of static firing tests:}

Horizontal test stand along with a set of measuring instruments were used in examining the TRM. The main function of this test facility is to measure the main loads acting on the TRM which are the internal pressure and the axial thrust force.

Three different main static firing tests were planned. Prior to performing these main tests, two preliminary static firing tests were conducted namely, a function static test and a sustaining static test. All these five tests were conducted in the same nominal environmental conditions namely, temperature of $20^{\circ} \mathrm{C}$ and pressure of 1 bar. Description and objective of each of the five tests are summarized in the following Table, 1.

Table 1 Plan of static firing tests

\begin{tabular}{|l|l|l|l|}
\hline Test & No. & Description & Objectives \\
\hline Function static test & 1 & $\begin{array}{l}\text { TRM fully equipped with } \\
\text { propellant charges without } \\
\text { measurement of any internal } \\
\text { ballistic parameters }\end{array}$ & $\begin{array}{l}\text { To verify the safe } \\
\text { operation and that the } \\
\text { TRM will withstand the } \\
\text { structural and thermal } \\
\text { stresses }\end{array}$ \\
\hline Sustaining static test & 1 & $\begin{array}{l}\text { TRM containing sustaining grain } \\
\text { only while the boosting chamber } \\
\text { is empty All sensors are } \\
\text { connected and are functioning } \\
\text { during the test }\end{array}$ & $\begin{array}{l}\text { To verify the propellant } \\
\text { internal } \\
\text { parameters. } \\
\text { To check safety and } \\
\text { measurement possibilities. }\end{array}$ \\
\hline Main static tests & 2 & $\begin{array}{l}\text { TRM fully equipped with } \\
\text { propellant charges. All sensors } \\
\text { are connected and are } \\
\text { functioning during the test. The } \\
\text { test is repeated to assess the } \\
\text { measurements }\end{array}$ & $\begin{array}{l}\text { To validate the theoretical } \\
\text { model }\end{array}$ \\
\hline Modified static test & 1 & $\begin{array}{l}\text { Minor modifications to the } \\
\text { grains and nozzles dimensions of } \\
\text { the basic test of the sonic case. }\end{array}$ & $\begin{array}{l}\text { To adjust the low pressures } \\
\text { in the main static tests. }\end{array}$ \\
\hline
\end{tabular}




\section{Results and Discussions:}

\subsection{Sustaining phase static test:}

The results (pressures and thrust time curves) of the sustaining static test case are presented in figures 3 and 4, respectively.

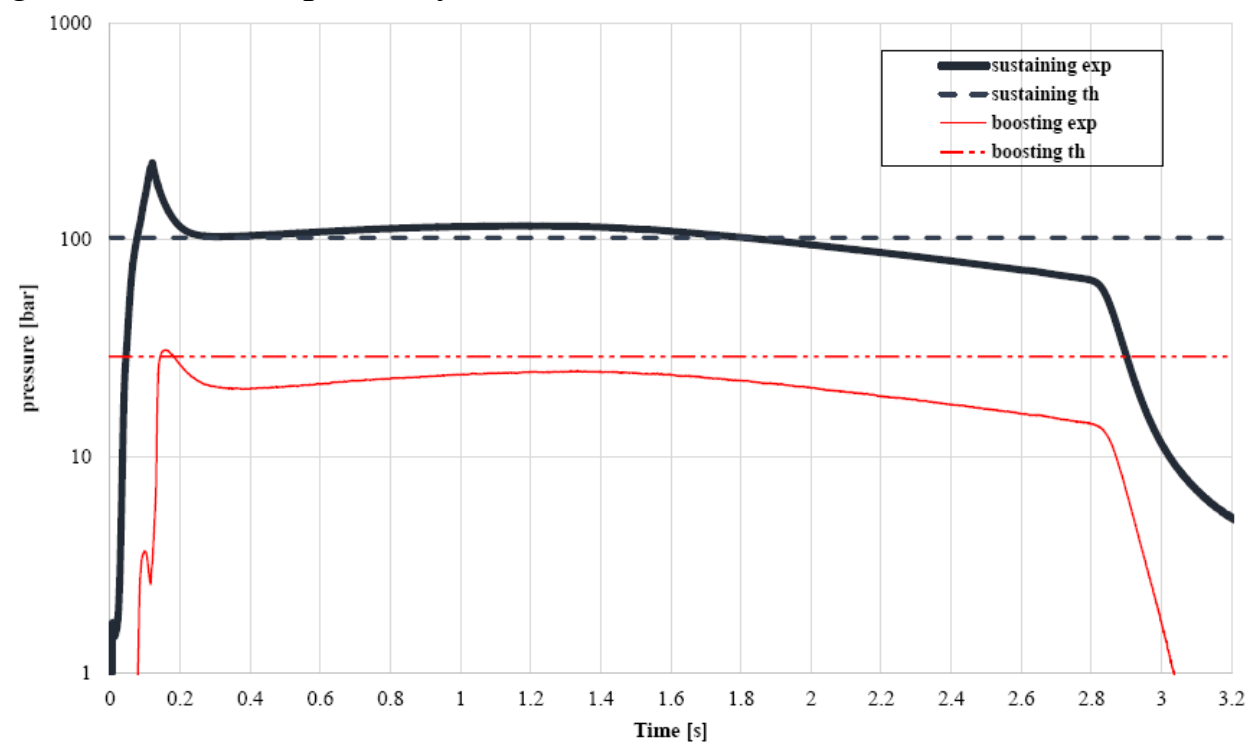

Figure 3 Pressure-time curves of the sustaining static test

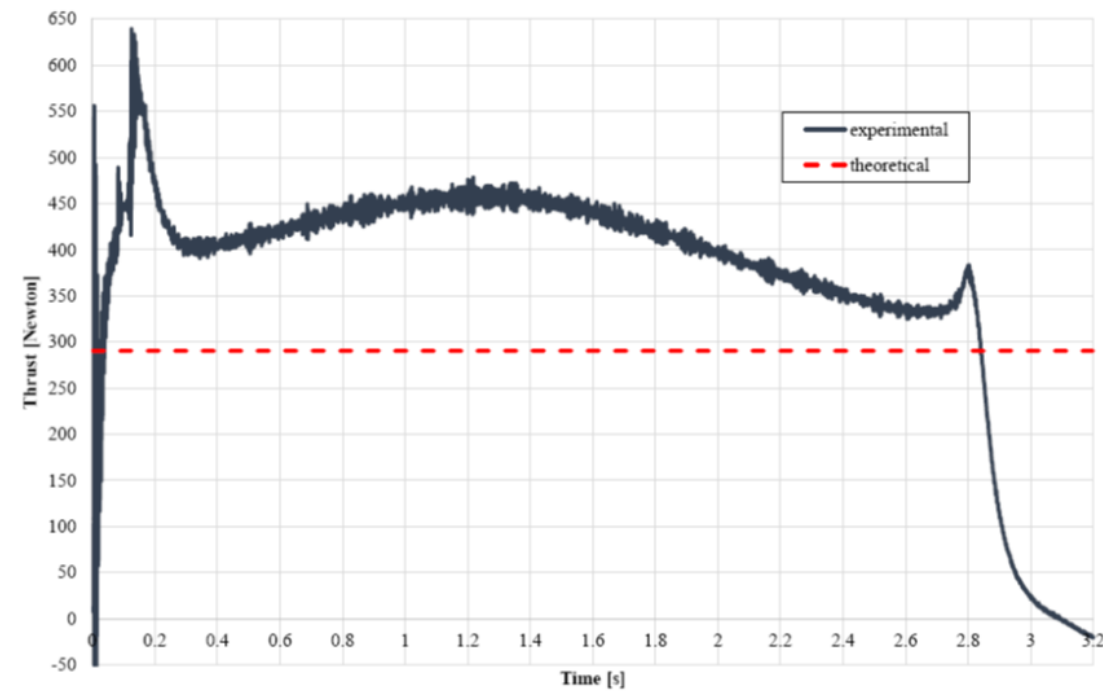

Figure 4 Thrust-time curve of the sustaining static test

In fig. 3, the sharp pressure rise at the start of motor operation is caused by the ignition charge located in the sustaining chamber reaching a value of about 226 bar. The gases produced by sustaining grain expand through the intermediate nozzle to a much lower value of about 31 bar that is sensed in the boosting chamber with time lag of about 0.035 seconds. After ignition phase, the sustaining grain starts burning yielding a combustion pressure of about 103 bar (similar to theoretical approach) that is reduced via expansion to about 21 bar in the boosting chamber (less than the theoretical approach). The sustaining chamber pressure increases gradually to a value of about 116 bar at 1.3 seconds of the motor function time and drops gradually afterwards until it reaches a value of about 68 bar. The tail-off phase of the pressure-time curves starts at about 2.8 seconds taking approximately 0.3 seconds.

The significantly high value of about 230 bar in fig. 3 may indicate an excessive amount of the igniter charge. Immediately after ignition, the end-burning grain in the sustaining chamber is expected to yield a constant pressure over its operation time as 
introduced before. However, a deviation from this trend is witnessed in the present test. The initial slight increase in the sustaining chamber pressure may be caused by the convexity of the burning surface taking place during its regression. The metallic walls of the chamber are heated up due to existence of hot gases. These hot walls may have the role of increasing the burning regression rate at the parts of the propellant adjacent to the walls. Also imperfections in grain outer surface insulation due to convexity may explain the slight increase in sustaining chamber pressure.

On the other hand, as the grain surface burns back, the free volume inside the chamber increases, the chamber pressure tends to decrease, and the burning rate drop down. The convexity of the burning surface is assumed to yield a zone of sliver which increases the free volume and reduces the actual burning surface. The combined effect of these factors may explain the gradual but significant drop (about 48 bar) in the sustaining chamber pressure towards the burnout of the grain.

Immediately after burnout, the accumulated gases exit the sustaining chamber causing the sharp drop in the chamber pressure. The intermediate nozzle has the continuing role of throttling the exhaust gases into the boosting chamber where they expand to a much lower pressure. The time lag of about 0.035 seconds can be addressed throughout the motor operation time.

Comparing the approaches (experimental and theoretical) in fig. 3, it can be seen that the average experimental sustaining chamber pressure almost coincides with the theoretical one while the experimental boosting chamber pressure is always less than the theoretical one. This may be owed to three factors. On the one hand, the losses in the TRM are not accounted for in the underlying isentropic assumptions of the theoretical model. This isentropic assumption leads to shorter burning times for the theoretical approach than those in the experimental one. On the other hand, convexity of the surface of burning may cause the slight increase in pressure that appears in the experimental reading. More importantly, the location of the pressure transducer in the boosting chamber may not be the proper one to measure the correct boosting pressure. An explanation of this aspect is attempted below.

Due to design constraint, the pressure transducer port inside the boosting chamber is located in the shadow of the jet exiting the intermediate nozzle as shown in fig. 5. The gas flow in the vicinity of the port may generate a vortex structure, leading to lower pressure.

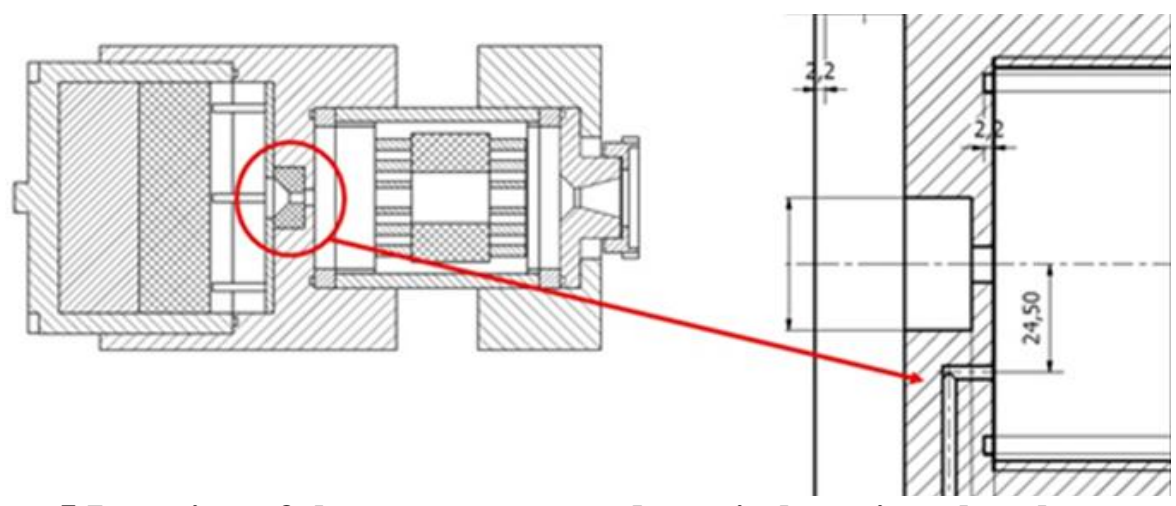

Figure 5 Location of the pressure transducer in boosting chamber

In fig. 4, the thrust follows fairly the same trend of boosting chamber pressure. The persisting rebels in thrust curve and the sudden spire at the onset of tail-off phase (at about 2.8 seconds) may all be owed to improper fixation of the TRM on the test bed. The sustaining 
thrust values (average $395 \mathrm{~N}$ ) are higher than the designed theoretical ones $(250: 300 \mathrm{~N})$. Further analysis showed that this discrepancy maybe owed to two factors.

On the one hand, the transducer that is used in the experiments with upper limit $10000 \mathrm{~N}$ has $1000 \mathrm{~N}$ limit for first-order measurements or $500 \mathrm{~N}$ limit for second-order measurements. So the designed sustaining thrust lies in the nonlinearity zone for the used transducer. On the other hand, the fixation of the TRM on the test bed followed by the over preloading value is the other cause for increasing the experimental sustaining thrust than the theoretical one. Normally, the preloading value should not exceed $30 \%$ of the expected thrust to be measured. This rule is violated due to the available fixation technique. This is more pronounced in the sustaining phase where the maximum expected thrust is about $300 \mathrm{~N}$ (30\% of the preloading value). The available facilities dictate using a pressurized air circuit having a clear leakage in the circuit. To overcome this leakage, over preloading value $(0.7: 0.92 \mathrm{v}$; equivalent to $900 \mathrm{~N}$ ) ought to be applied.

It should be noted that, since the present experiments deal with DTRM, rules for the presetting loads would have been violated especially during the sustaining phase in all cases. In fact, designing a presetting technique that automatically changes the presetting load value may be unattainable.

\subsection{Main static tests:}

A basic firing test is carried out for the designed TRM and is repeated to confirm and assess the results. Dimensions of grains and nozzles are listed in Table 2, followed by the pressure and thrust time curves for each test (Figures 6 to 11). For the sake of comparison, the corresponding theoretical results for the basic and repeated tests are plotted in these figures.

Table 2 Grains and nozzles dimensions for DTRM

\begin{tabular}{|l|c|}
\hline \multicolumn{1}{|c|}{ Name } & Value \\
\hline Sustaining grain (outer diameter x its length) $[\mathrm{mm}]$ & $110 \times 25$ \\
\hline Boosting grain (outer diameter x inner diameter x its length) $[\mathrm{mm}]$ & $63.6 \times 24.5 \times 33$ \\
\hline Main nozzle (throat diameter x exit diameter) [mm] & $9.58 \times 20$ \\
\hline Intermediate nozzle (throat diameter) $[\mathrm{mm}]$ & 4.98 \\
\hline
\end{tabular}

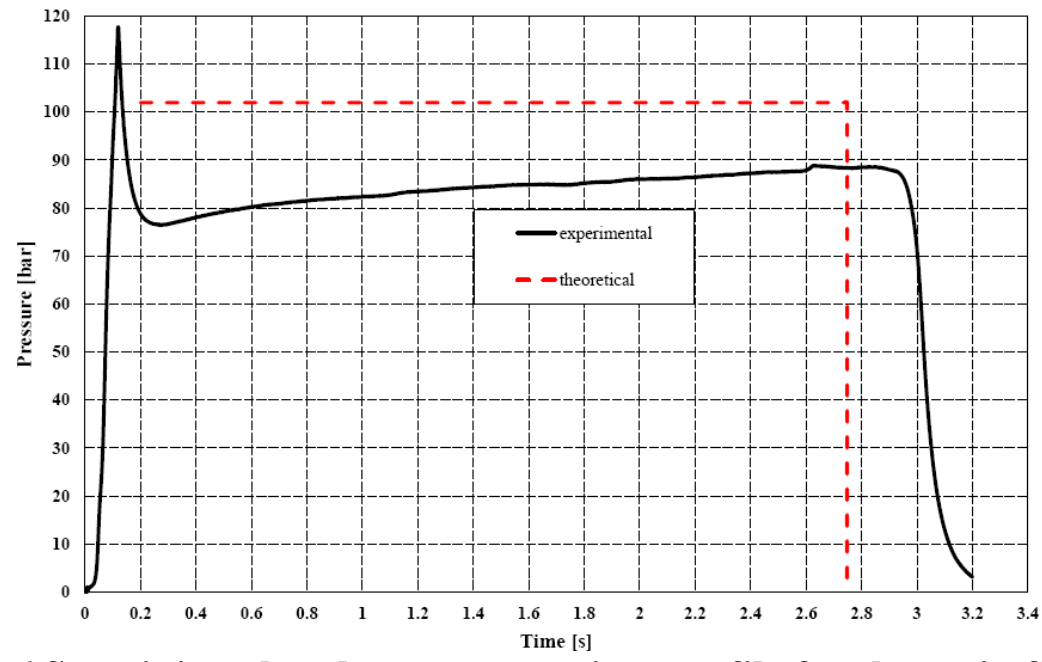

Figure 6 Sustaining chamber pressure-time profile for the main firing test 


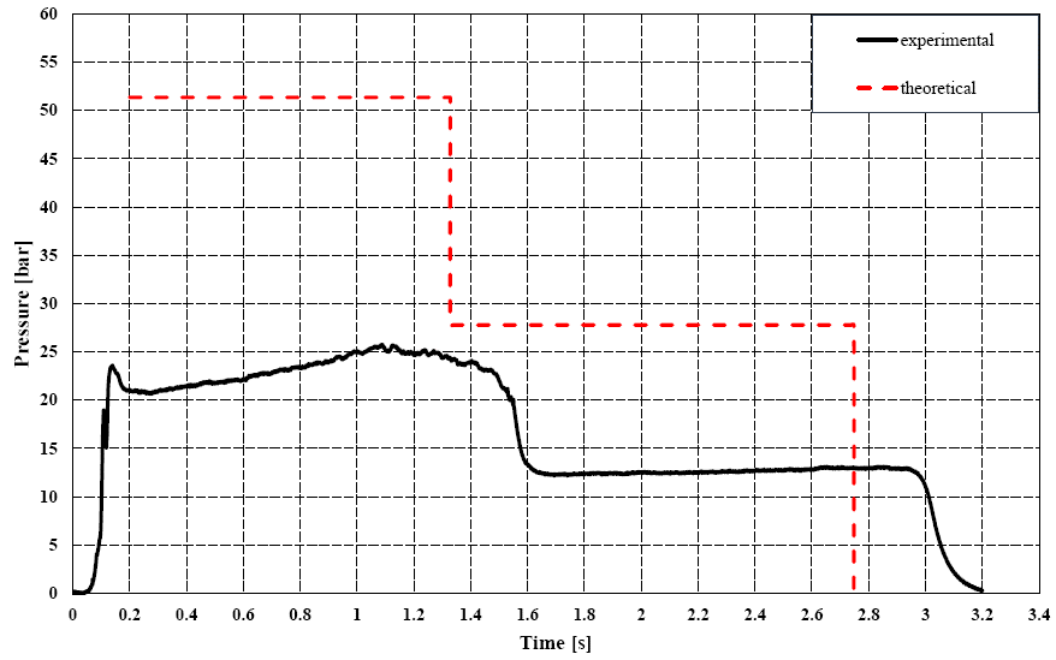

Figure 7 Boosting chamber pressure-time profile for the main firing test

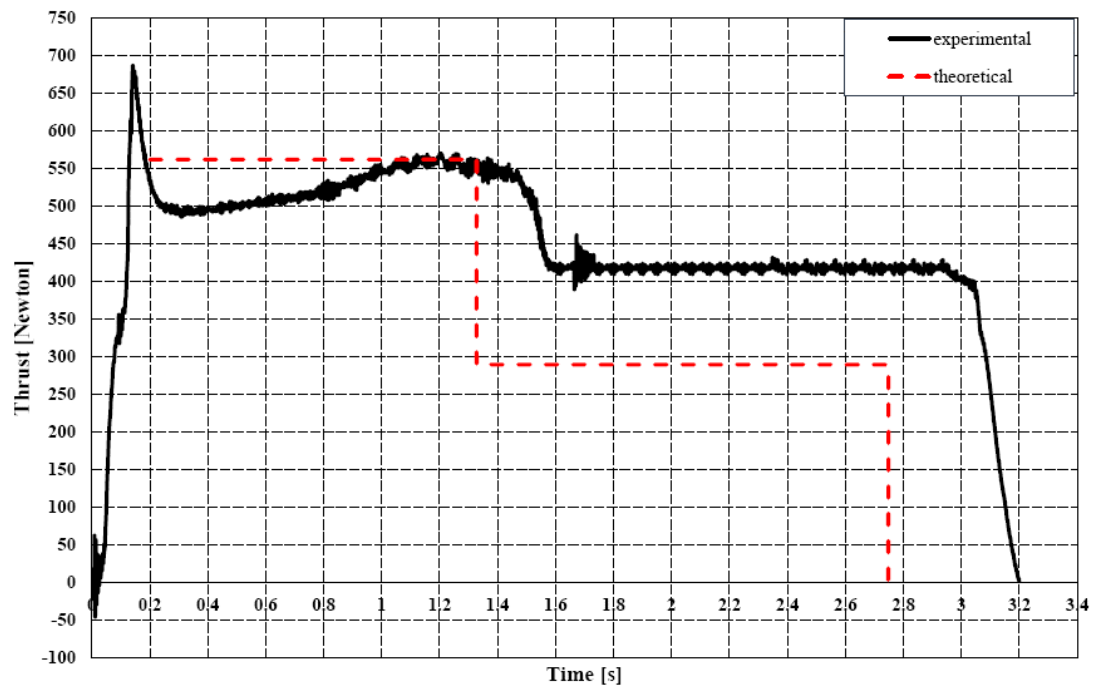

Figure 8 Thrust-time profile for the main firing test

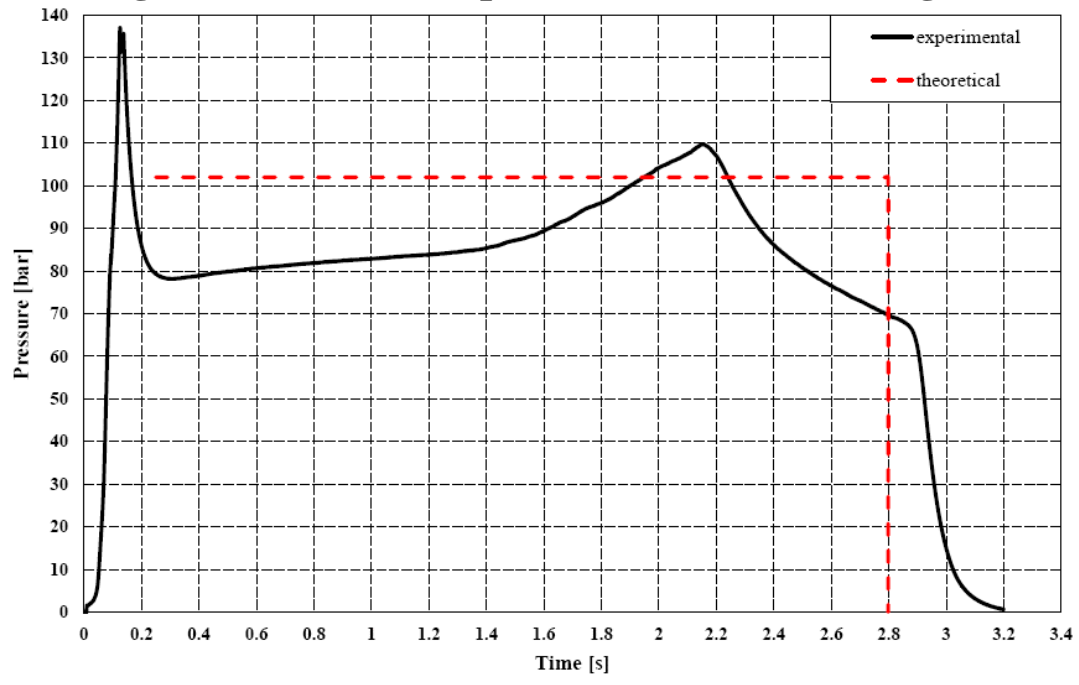

Figure 9 Sustaining chamber pressure-time profile for the repeated firing test 


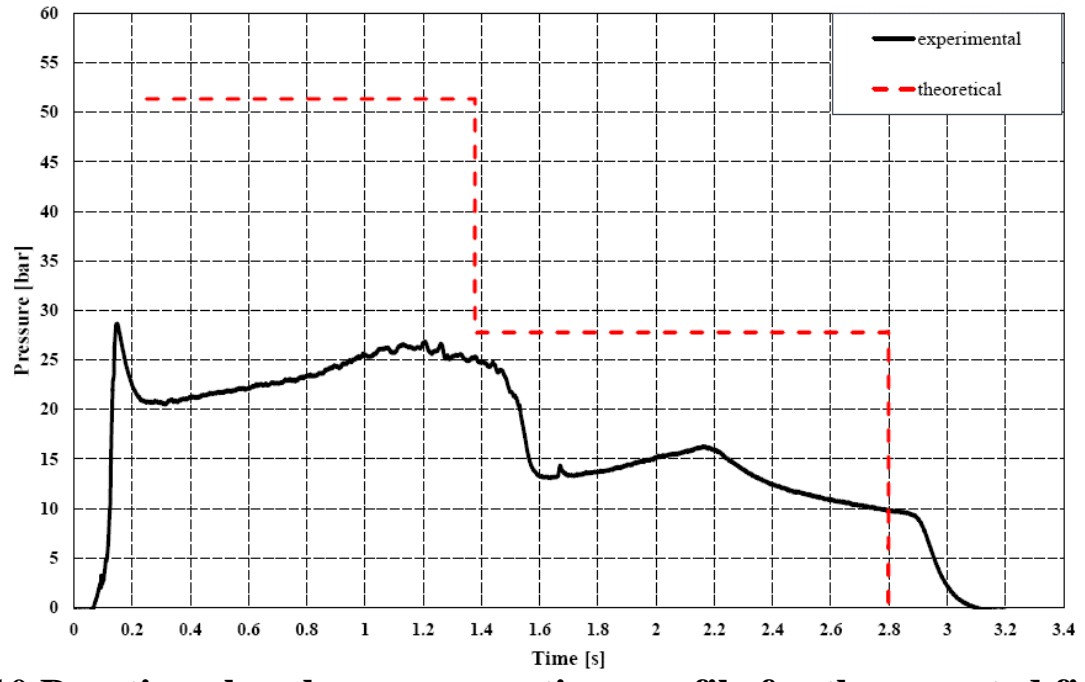

Figure 10 Boosting chamber pressure-time profile for the repeated firing test

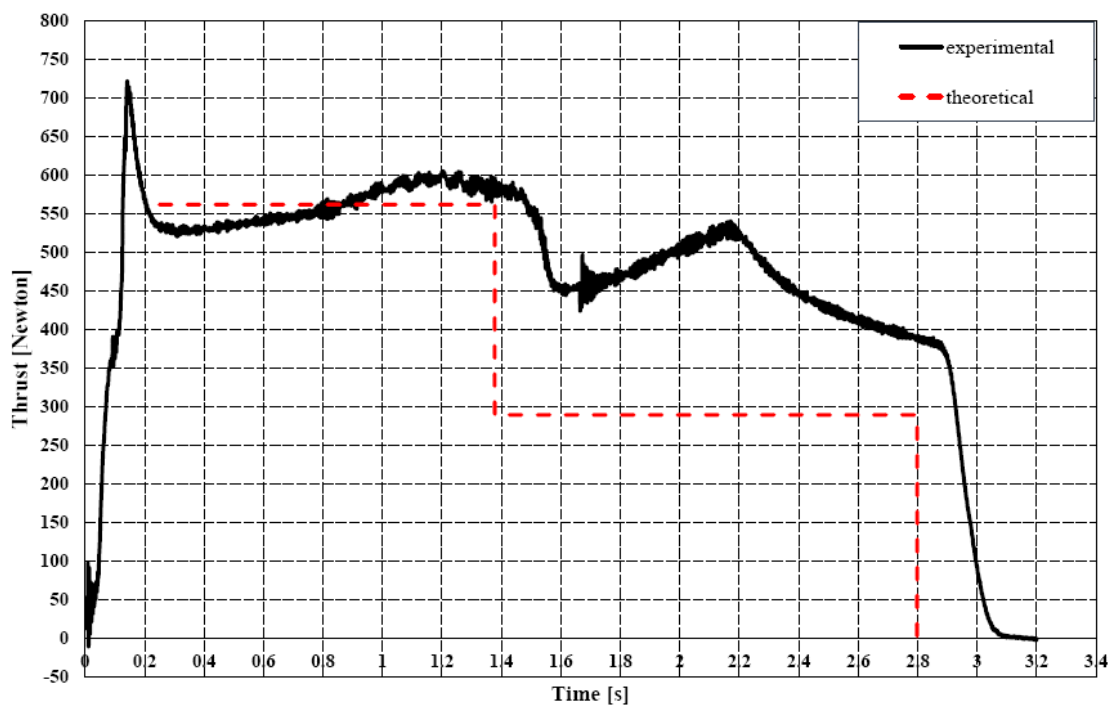

Figure 11 Thrust-time profile for the repeated firing test

Pressure-time curves of the sustaining chamber from the experiment and the corresponding theoretical prediction are shown in Fig. 6. The theoretical curve appears constant at operating pressure 103 bar taking a time of operation of about 2.74 seconds. In contrast, the experimental curve ascends sharply in approximately 0.2 seconds during the ignition phase that is not considered in the theoretical model. During the steady-state phase, the measured pressure starts at about 80 bar, increase up to 88.5 bar taking about 3 seconds of operating time. Looking at the tail-off phase, the measured pressure decreases sharply in about 0.2 seconds as the propellant grain is burned out.

Figure 7 shows the pressure-time curves of the boosting chamber for the experimental measurement and theoretical prediction. The theoretical curve starts with a constant operating pressure 51.5 bar taking 1.334 seconds operating time during the boosting phase then sharply falls down to 27.8 bar of a constant operating pressure during the sustaining phase which terminates at 2.74 seconds. In the experimental reading, the boosting phase starts operating at 22 bar that increases gradually to about 25 bar and lasts for 1.55 seconds operating time then the sustaining phase operates at a nearly constant pressure of 13 bar till the propellant burnout at 3.2 seconds operating time. 
Finally, the thrust-time curves of this case are shown in Fig. 8. The theoretical thrusttime curve appears constant at $561.4 \mathrm{~N}$ during the boosting phase time of 1.334 seconds. In the sustaining phase, the thrust falls down to $289.2 \mathrm{~N}$ and terminates after 2.74 seconds. In the boosting phase of the experiment, the thrust increases gradually from $500 \mathrm{~N}$ to about $550 \mathrm{~N}$ for 1.55 seconds while the sustaining phase produces $415 \mathrm{~N}$ thrust for 1.65 seconds of operating time. Figures 10 to 12 have the same trend similar to figures 7 to 9 respectively.

The measured pressure of the exhaust gases inside the boosting chamber during the sustaining phase is impractically low (about 13 bar). In practice, the low pressure value would yield sustaining thrust too low for real application. Consequently, another experiment is performed to adjust this low pressure. This is achieved with minor modifications to the grains and nozzles dimensions of the basic test. The length of the boosting grain and the critical diameter of the main nozzle are slightly increased such that the condition in equation (1) is still valid. Grains and nozzles dimensions for the modified case are listed in Table 3. The pressure and thrust time curves for modified TRM are presented in figures 12 to 14 .

Table 3 Grains and nozzles dimensions for the modified DTRM

\begin{tabular}{|l|c|}
\hline \multicolumn{1}{|c|}{ Name } & Value \\
\hline Sustaining grain (outer diameter $\mathrm{x}$ its length) $[\mathrm{mm}]$ & $110 \times 25$ \\
\hline Boosting grain (outer diameter x inner diameter x its length) $[\mathrm{mm}]$ & $63.6 \times 24.6 \times 43$ \\
\hline Main nozzle (throat diameter x exit diameter) $[\mathrm{mm}]$ & $9.7 \times 20$ \\
\hline Intermediate nozzle (throat diameter) $[\mathrm{mm}]$ & 4.98 \\
\hline
\end{tabular}

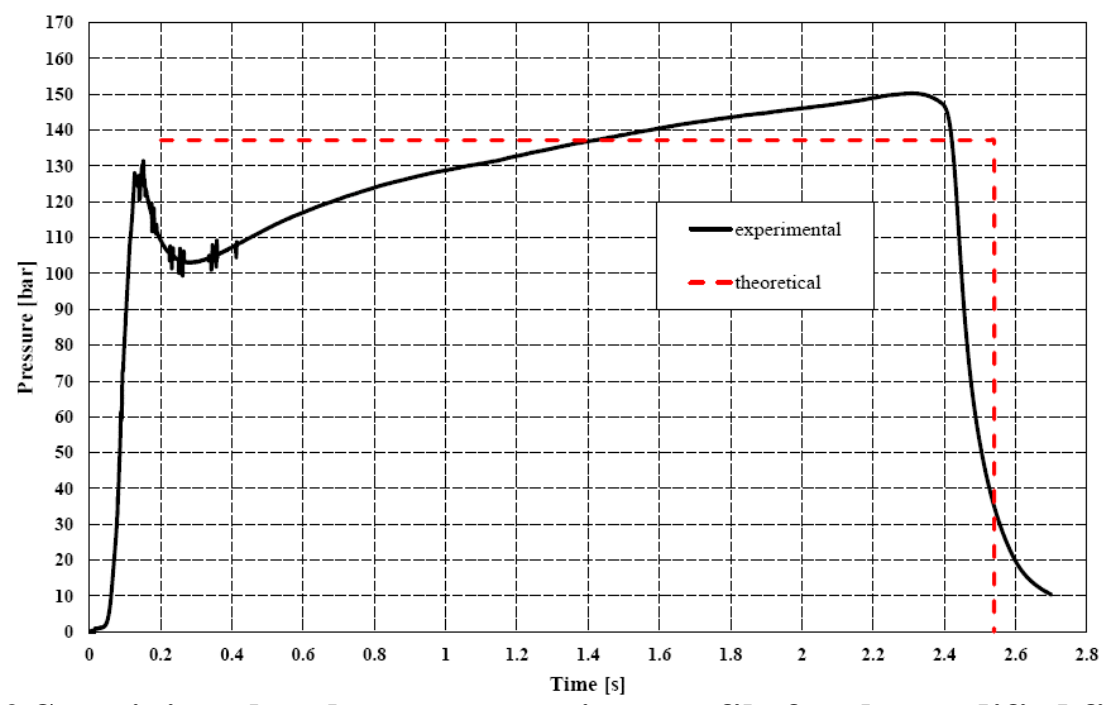

Figure 12 Sustaining chamber pressure-time profile for the modified firing test 


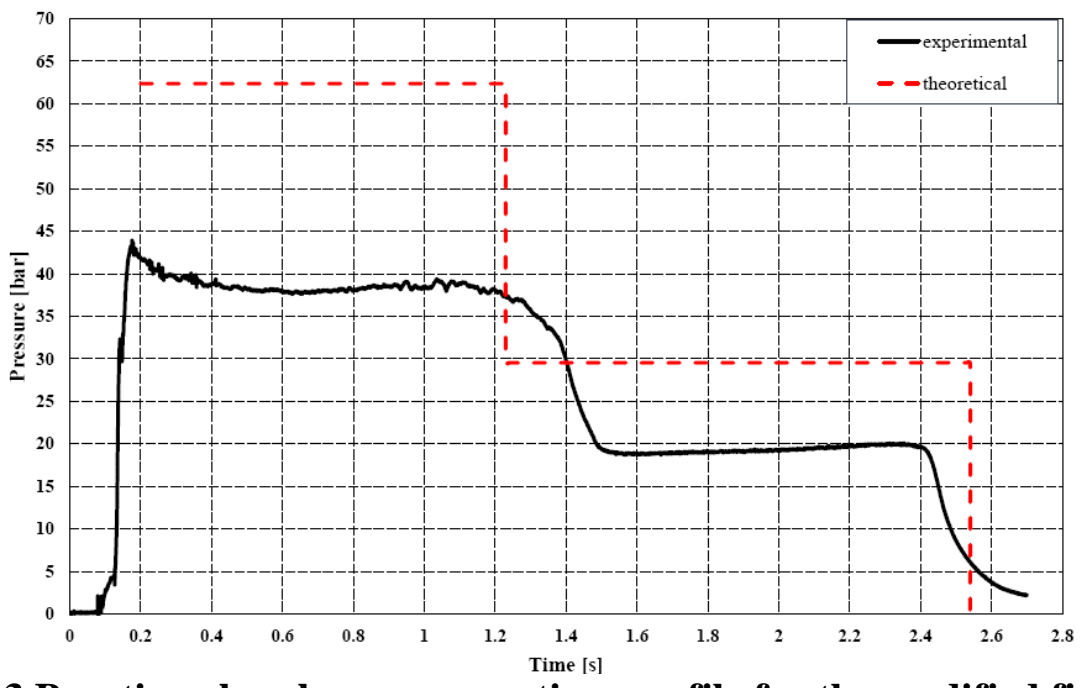

Figure 13 Boosting chamber pressure-time profile for the modified firing test

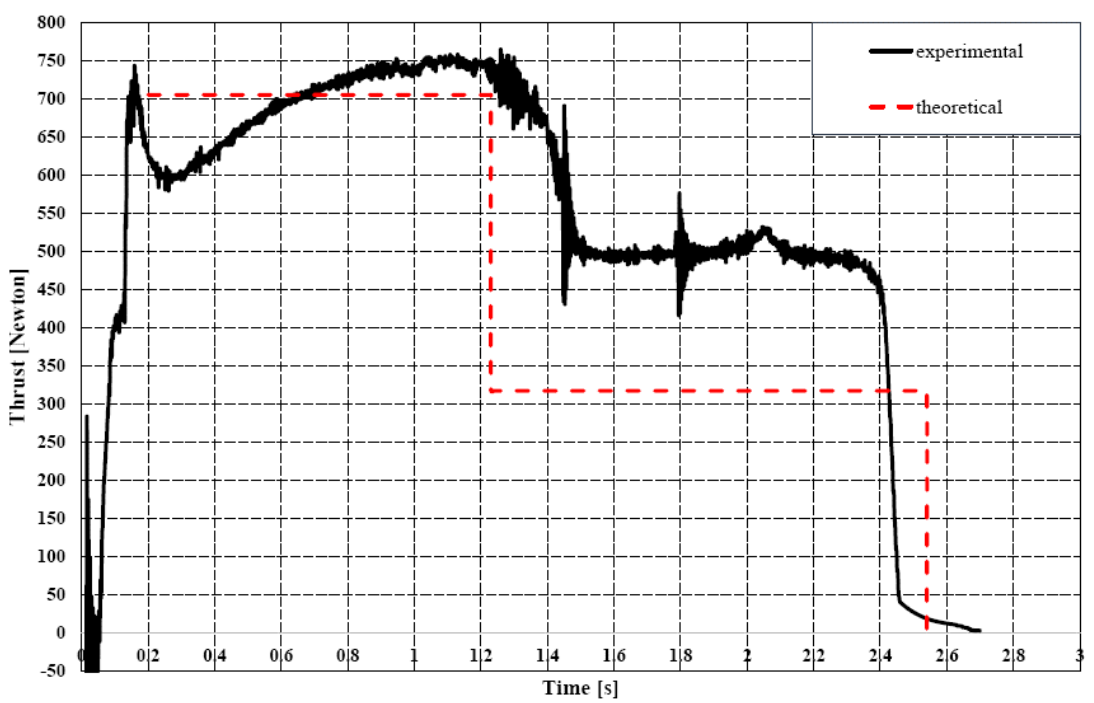

Figure 14 Thrust-time profile for the modified firing test

Figure 12 shows the pressure-time curves of the sustaining chamber for the experimental reading and theoretical prediction. The theoretical curve appears constant at operating pressure of 137.16 bar taking a time of operation 2.54 seconds. The experimental one ascends sharply in approximately 0.2 seconds during the ignition phase. During the steady-state phase, the measured pressure starts at 103 bar, increases to 150 bar taking about 2.4 seconds operating time. Looking at the tail-off phase, the operating pressure decrease sharply as the propellant grain is burned out in 0.2 seconds.

Figure 13 compares the experimental measurements and theoretical predictions of the pressure-time curves of the boosting chamber. The theoretical curve starts with a constant operating pressure of 62.35 bar taking 1.23 seconds operating time during the boosting phase then sharply falls down to the constant value of 29.5 bar during the sustaining phase which lasts for 2.54 seconds. In the experimental curve, the boosting phase operates approximately at 38 bar for 1.4 seconds operating time then the sustaining phase starts roughly at 20 bar till the propellant burnout after 1.32 seconds.

Finally, the thrust-time curves of this case are shown in Fig. 14. The theoretical thrusttime curve appears constant during the boosting phase duration of 1.23 seconds producing a thrust of $704.85 \mathrm{~N}$. Then, the sustaining phase falls down to $317.16 \mathrm{~N}$ and terminates after 
2.54 seconds. In the boosting phase of the experimental curve, this TRM yields approximately $675 \mathrm{~N}$ thrust for 1.4 seconds while in the sustaining phase, it produce $500 \mathrm{~N}$ thrust for 1.32 seconds operating time.

Closely examining figures 6,9 and 12, the boosting and sustaining phases cannot be distinguished neither in the experimental nor in the theoretical approaches. This may be owed to the fact that the sustaining pressure is not affected by the boosting pressure due to the presence of choking in the intermediate nozzle. Generation of the choking makes the downstream chamber practically independent of the upstream one. In Fig. 6, there is a significant difference between the theoretical and experimental pressure values as explained earlier. Fig. 9 has the same behavior of fig. 6 except for the gradual increase of experimental pressure values in the interval of time between 1.8 to 2.2 seconds. This may be due to the possible propellant inhomogeneity and a sudden increase of the surface area of burning possibly caused by any cracks on the surface of the grain. In Fig. 12, the clear trend of increase in the measured pressure may support the increase of the surface area of burning of the sustaining grain. But, the average measured pressure is close to the value predicted by the theoretical model.

In contrast, by closely examining figures 7, 10 and 13, differentiation between the two phases (boosting and sustaining) is clear. It is also clear that there is a steady drop between theoretical approach and experimental one. It can be seen also that this pressure-time trend in figures 7,10 and 13 dictates the thrust-time trend shown in figures 8, 11 and 14, respectively. The TRM produces a thrust ratio 1.35 for the basic and repeated tests and 1.5 for the modified test.

In fig. 13, it is apparent that the experimental results were improved and became closer to the theoretical results in comparison with the data listed in figures 7 and 10 . Comparing the approaches (experimental and theoretical) in figures 7, 10 and 13, it can be seen that the experimental boosting chamber pressures is always less than the theoretical one due to the improper location of the pressure transducer in the boosting chamber.

From figures 8, 11 and 14, the boosting and sustaining phases are clear and the dualthrust phenomena appear but with low thrust ratio (average 1.4 thrust ratio). It is apparent that the experimental values are higher than the theoretical ones in the sustaining phase. This is due to the fact that the gases are expanded in the boosting chamber to lower pressure. This low value yields a significantly long time of stay for combustion gases which allows the shift in equilibrium to occur. This means that the gas products will be dissociated reducing the molecular mass of the gases which improve the thrust in this phase. This phenomena appears also in figure 5. The transducer that is used in the experiments and the available fixation technique of the TRM (as explained earlier) may cause the significant increase in the experimental thrust values.

\section{Conclusions:}

The objective of the present study was to understand the physics of internal ballistics of DTRM in the specific case where a sonic flow takes place through the intermediate nozzle.

A mathematical model has been developed and a set of static firing tests have conducted in a specially-designed TRM. The main conclusions of this study are as follows:

1. In the boosting phase, the combustion gas pressure in the sustaining chamber is independent of the combustion gas pressure in the boosting one. This may be attributed to flow choking in the intermediate nozzle.

2. The thrust of the sustaining phase is higher than that expected by the theoretical analysis. This is due to the staying of the combustion gases for a 
considerable time in the boosting chamber at lower pressure, which allows the gases to reach new equilibrium dissociate to smaller molecular mass which improve the thrust of this phase.

3. Both trends in theoretical analysis and experimental investigation are fairly comparable. However, considering transient conditions would improve the theoretical results.

The present study can be extended in view of enhancing the developed mathematical model in terms of incorporating ignition and tail-off phases.

\section{References:}

[1] G. Sutton, Rocket Propulsion Elements, seventh ed.: JOHN WILEY \& SONS, INC., 2001

[2] H. M. Darwell, "Solid Propellant Dual-Thrust Motors," Proceeding of the 1 st Rocket Propulsion Symposium, 1961.

[3] McFillin, J. F., Van Brocklin, S. T., Beakley, J. E., and Netzer, D. W., "Dual-Chamber Roicekt Motor Operating Characteristics," Journal of Space Craft and Rockets, Vol. 21, No. 2, 1984, pp. 168- 174.

[4] Carrier, J. L., Constantinou, T., Harris, P. G., and Smith, D. L., "Dual-InterruptedThrust Pulse Motor," Journal of Propulsion and Power, Vol. 3, No. 4, 1987, pp. 308312.

[5] Manda, L. J., "Boost-Phase Equilibrium Pressures in a Dual-Thrust Soil-Propellant Rocket Motor," Journal of Spacecraft and Rockets, Vol. 2, No. 4, 1965, pp.607-609.

[6] M. Barrerre, Rocket Propulsion: Elsevier Pub. Co., 1960.

[7]B. P. Dunn. (2013, Cited Jan. 2013). "Rocket Engine Specific Impulse Program," http://www.dunnspace.com/isp.htm. 